\title{
Impact of Indochina Deforestation on the East Asian Summer Monsoon*
}

\author{
Omer Lutfi Sen, Yuging Wang, AND Bin Wang \\ International Pacific Research Center, School of Ocean and Earth Science and Technology, \\ University of Hawaii at Manoa, Honolulu, Hawaii
}

(Manuscript received 24 March 2003, in final form 28 July 2003)

\begin{abstract}
This paper describes a study that investigates the local and remote effects of Indochina deforestation on the east Asian summer monsoon. During the summer months, the peninsula is subject to strong monsoonal flow whose downstream rainfall is of vital importance for China, where a significant fraction of the world's population lives. It is, therefore, extremely important to investigate how the landscape change affects this monsoonal flow, and whether this effect is strong enough to cause notable changes in the regional rainfall. For this reason, a modeling experiment with the International Pacific Research Center regional climate model was carried out. Ensemble simulations with the current vegetation cover in the peninsula and its reforested scenario were performed for the period from 20 April to 31 August 1998. The results of the experiment indicate that deforestation in the peninsula has not only local, but also far-reaching effects on the east Asian summer monsoon. Locally, the effect could be described as increases in wind speed and temperature, and as a decrease in water vapor mixing ratio from the surface up to about $850 \mathrm{mb}$. Furthermore, the deforestation tends to enhance the rising motions, and, hence, tends to reduce surface pressure and geopotential height up to about $850 \mathrm{mb}$ over the deforested area. The local landscape changes tend to increase rainfall on the downwind side and decrease it on the upwind side. Far-reaching effects in summer include a weakening of the monsoonal flow over east China, near the Tibetan Plateau, and a strengthening over the neighboring seas to the east. These changes yield sandwichtype drier and wetter bands that are elongated along the main flow path of the east Asian summer monsoon. A comparison of the modeled changes with the observed rainfall trends suggests that the deforestation in the Indochina Peninsula could be one of the major factors causing changes in the climate of the region.
\end{abstract}

\section{Introduction}

Earth's land surface interacts with the overlying atmosphere, and modifying the surface cover affects land surface-atmosphere interaction processes and, hence, the exchange of energy, momentum, water vapor, and other trace gases. Rapid replacement of rain forests by pasture and agricultural fields, therefore, has the potential to affect the regional and global climate systems. This has led the scientific community to study deforestation and assess its effects on climate over the last two decades or so. Field observations have been carried out to advance our knowledge on the micrometeorology of rain forests and deforested areas (e.g., Shuttleworth et al. 1991; Gash et al. 1996). The data collected in these field campaigns proved valuable for improving the representation of land surfaces in general circulation

\footnotetext{
* International Pacific Research Center Contribution Number IRPC-257 and School of Ocean and Earth Science and Technology Contribution Number 6324.
}

Corresponding author address: Dr. Yuqing Wang, IPRC/SOEST, University of Hawaii at Manoa, 2525 Correa Road, Honolulu, HI 96822.

E-mail: yuqing@hawaii.edu models (GCMs) as well (e.g., Sellers et al. 1989; Sen et al. 2001; among others). Studies using GCMs have been conducted (e.g., Dickinson and Henderson-Sellers 1988; Nobre et al. 1991; Lean and Rowntree 1993; Hahmann and Dickinson 1997; among several others) on the effect of rain forest clearing on regional and global climates. Most of these studies, however, have looked into the deforestation in Amazonia, where the world's largest rain forest lies. Few studies have investigated the impact of deforestation in tropical Asia (e.g., Henderson-Sellers et al. 1993; McGuffie et al. 1995; Kanae et al. 2001).

It is widely recognized that deforestation causes substantial changes in two surface parameters-an increase in albedo and a decrease in surface roughness. The albedo change may be more significant if the forest is replaced with pasture, as in Amazonia, than if it is replaced with agricultural fields, as in the Indochina Peninsula (IP), because the albedo change from rain forest to agricultural fields is smaller than that from rain forest to pasture (Giambelluca et al. 1999). Increased albedo results in a reduction in surface net radiation, which then leads to a reduction evapotranspiration. The smaller water vapor transport to the atmosphere from the surface reduces the precipitable water in the atmosphere, hence, 
the rainfall. Reduced roughness from deforestation can have a similar effect but through reducing surface drag. Pielke (2001) suggests two ways in which a land surface change, including deforestation, can affect local and regional heat and moisture fluxes: the change in the Bowen ratio that results from the change in surface heat and moisture budgets can directly alter the local and regional convective available potential energy (CAPE); and the changes in the large-scale atmospheric pressure field, resulting from the landscape change, can alter the largerscale heat and moisture convergence and associated large-scale wind circulations. All of these changes are expected to make persistent changes in the local and regional climate.

The deforestation studies, whether they are based on field experiments or model experiments, agree on one thing: deforestation affects weather and climate. The majority of the GCM sensitivity experiments of complete deforestation in the Amazon basin finds significant reductions in precipitation, evapotranspiration, and moisture convergence over the basin (e.g., Lean and Rowntree 1993; Hahmann and Dickinson 1997; among several others). There are, however, a few experiments that report conflicting results, such as an increase in precipitation (e.g., Polcher and Laval 1994) and an increase in moisture convergence (e.g., Lean et al. 1996; Polcher and Laval 1994). Even experiments that draw similar conclusions vary considerably with regard to the magnitude of the changes in the above fields. Observations so far do not confirm a significant reduction in rainfall over Amazonia, although the extent of deforestation is still much smaller than what has been modeled in the above experiments. Chu et al. (1994), for instance, found no significant change in rainfall due to deforestation in the Amazon basin by analyzing outgoing longwave radiation between 1974 and 1990, albeit the period was relatively short. More recently, Easterling et al. (2000) showed increasing trends in precipitation over most of the Amazon basin based on centurylong trends. Chen et al. (2001) suggested that the interdecadal change in the global circulation might have suppressed the impacts of tropical deforestation. Largescale atmospheric circulation and associated moisture convergence can, therefore, alter the deforestation effect and cause changes in the regional climate that are different from those that one would expect from common understanding. Based on station data from Thailand between 1951 and 1994, Kanae et al. (2001) report for the IP that significant reductions in precipitation occur only in September, and the authors relate this to the disappearance of strong external forcing (Indian monsoonal westerlies) during this month. They suggest that the deforestation significantly affects the local atmosphere only with the Indian monsoonal westerlies disappear over the IP, which usually occurs in September. The above studies suggest that factors such as the extent of the deforested area, the strength of the external forcing, the moisture convergence, the effect of interannual and interdecadal variability, etc., may play opposing roles in the impact of the deforestation on the climate, and that more research is needed to study these factors to advance our knowledge further.

In this study, we focus on the IP deforestation whose effects on the local and regional climate have been studied little. There is no reliable historical data on deforestation in the peninsula, which has likely been subject to deforestation for a long time. However, it is known that the rate of deforestation in the peninsula dramatically increased in the twentieth century as the population substantially increased. Especially after 1955, the forested area in the peninsula has been substantially reduced (see, e.g., Fig. 1 of Kanae et al. 2001). Between 1973 and 1985, when the most dramatic deforestation occurred in the peninsula-Thailand lost $26 \%$ of its forest cover, Cambodia 24\%, Vietnam 19\%, Laos 10\%, Myanmar 8\%, with a total of $14 \%$ (Tropical Rain Forest Information Center, Michigan State University). The primary reason for deforestation was logging in and expansion of the agricultural fields. Although it has slowed in recent years, deforestation in the IP has already reached an extent that may have serious regional impacts on climate.

The primary objective of this study is, thus, to investigate the impact of the Indochina deforestation on the east Asian summer monsoon (EASM), especially on its rainfall. During the summer months, monsoonal flow originating from the Indian Ocean brings abundant moisture to China and other countries in the region, in which a considerable population depends on its rainfall. This monsoonal flow passes the IP before reaching the South China Sea (SCS) and China. As mentioned earlier, Kanae et al. (2001) reported that the decreasing trend in rainfall due to deforestation was evident only in September when the monsoonal flow weakened, and they suggested that the effect of deforestation was flushed away by the strong monsoonal flow during the summer months. This implies that the deforestation effect is conserved in the monsoonal flow and may, therefore, have an impact on the downstream processes. Given that the monsoon brings both needed rainfall and occasional devastating floods to the heavily populated region, it becomes extremely important to investigate whether the deforestation in the IP affects the downstream rainfall. For this reason, ensemble simulations with the current vegetation cover in the IP and its reforested scenario were carried out using a state-of-the-art regional climate model. The reforestation scenario in the model might not be entirely realistic because of the uncertainty about the extent of deforestation, but we think that it is a close approximation to reality, given the fact that much of the deforestation occurred during the last century. The experiment was performed using data from the 1998 summer monsoon, which was a relatively wet summer with large floods in China. In that sense, this experiment quantifies the impact of the deforestation in the IP on the EASM in an extreme year. Nevertheless, it provides 
significant evidence that the deforestation in the IP has the potential to have significant impact on the EASM, and, hence, the climate of the region.

The present paper is organized as follows. Section 2 briefly describes the regional climate model used in this study, the experimental design, and the EASM. The results of the study are given in section 3 . The model performance, local and large-scale atmospheric changes, changes in rainfall and its frequency, and observed rainfall trends are all provided in this section. A summary and conclusions are given in section 4 .

\section{Model, experimental design, and the east Asian summer monsoon}

\section{a. Model}

The highly resolved regional climate model (IPRCRegCM) developed at the International Pacific Research Center (IPRC) (Wang et al. 2003) uses hydrostatic primitive equations in spherical coordinates with sigma (pressure normalized by surface pressure) as the vertical coordinate. The model has 28 vertical levels with variable resolution - the highest resolution being in the planetary boundary layer. The comprehensive cloud microphysics scheme developed by Wang (1999, 2001) represents the grid-scale moist processes. Subgrid convective processes, such as shallow convection, midlevel convection, and penetrative deep convection, are based on the mass flux cumulus parameterization scheme originally developed by Tiedtke (1989) and later modified by Nordeng (1995). This modified version uses a CAPE closure and considers the organized entrainment and detrainment based on a simple cloud plume model. The subgrid-scale vertical mixing is accomplished by the socalled $E-\varepsilon$ turbulence closure scheme (Detering and Etling 1985). Surface fluxes over oceans are calculated based on the Monin-Obhukov similarity theory (Wang 2002). The radiation package was originally developed by Edwards and Slingo (1996) and further improved by Sun and Rikus (1999). Cloud amount is diagnosed by using the semiempirical cloudiness parameterization scheme developed by Xu and Randall (1996).

For the land surface processes, the model uses the Biosphere-Atmosphere Transfer Scheme (BATS) developed by Dickinson et al. (1993). BATS incorporates one canopy and three soil layers, and it requires land cover/vegetation (18 types) and soil texture (12 types) maps for spatial applications, as in a GCM. In our application, these datasets were obtained from the U.S. Geological Survey (USGS; the second version of the USGS 1-km resolution land cover classification dataset), and the U.S. Department of Agriculture (global 10-km soil data). Similar to most other grid-point regional climate models, a one-way nesting is used to update the model time integration in a buffer zone near the lateral boundaries.

\section{b. Experimental design}

The IPRC-RegCM was used to carry out two ensemble simulations, each with five members with different initial conditions spanning 5 days, centered on 20 April 1998. The current surface cover was used in one ensemble (hereafter CURRENT), while a reforestation scenario was used in another (hereafter FOREST). In the FOREST simulations, the grids with the "irrigated crop" vegetation class of BATS - those falling between $9^{\circ}-19^{\circ} \mathrm{N}$ and $94^{\circ}-109^{\circ} \mathrm{E}$ (see the box in Fig. 1) -were replaced with the "evergreen broadleaf" vegetation class. By definition in BATS, the roughness length is $2.0 \mathrm{~m}$ for the evergreen broadleaf and $0.06 \mathrm{~m}$ for the irrigated crop class; the vegetation albedo is 0.04 for wavelengths smaller than $0.7 \mu \mathrm{m}$ and 0.20 for those larger than $0.7 \mu \mathrm{m}$ for the evergreen broadleaf class, and 0.08 for wavelengths smaller than $0.7 \mu \mathrm{m}$ and 0.20 for those larger than $0.7 \mu \mathrm{m}$ for the irrigated crop.

The European Centre for Medium-Range Weather Forecasts (ECMWF) global analysis data were used to define the driving fields, which provide both initial and lateral boundary conditions to the regional climate model. Sea surface temperatures (SSTs) over the ocean were obtained from the Reynolds weekly SST data (Reynolds and Smith 1994). Initial soil moisture fields were initialized such that the initial soil moisture depends on the vegetation and soil type defined for each grid cell (depth of soil $\times$ field capacity $\times$ porosity).

The model domain (see Fig. 1) covers the area $0^{\circ}-$ $55^{\circ} \mathrm{N}, 80^{\circ}-140^{\circ} \mathrm{E}$ with horizontal grid spacing of $0.5^{\circ}$. The USGS high-resolution topographic dataset $\left(0.0833^{\circ}\right.$ $\times 0.0833^{\circ}$ ) was used to obtain the model topography (see Fig. 1). The high-resolution vegetation type data from USGS are reanalyzed to represent the dominant vegetation type in each grid box, except in the reforestation scenario where the agricultural fields in the IP were just replaced with tropical rain forest (see Fig. 1). The model was initialized at 0000 UTC on 20 April 1998, and integrated continuously through 31 August. The results are reported in terms of the averages of each ensemble.

The performance of the model was assessed by comparing the CURRENT simulation with independent station data available for the model domain. Statistics similar to those used by Wang et al. (2003) were utilized to assess the different aspects of the model performance, including model bias from the observations, temporal and spatial pattern correlation coefficients between the model simulation and observations, and the spatial standard deviation. Before calculation of objective statistics, all of the station data were distributed to the model grid system by the triangle-based cubic spline interpolation algorithm.

\section{c. The 1998 east Asian summer monsoon}

Because detailed information on the EASM and its 1998 evolution can be found in several other sources 


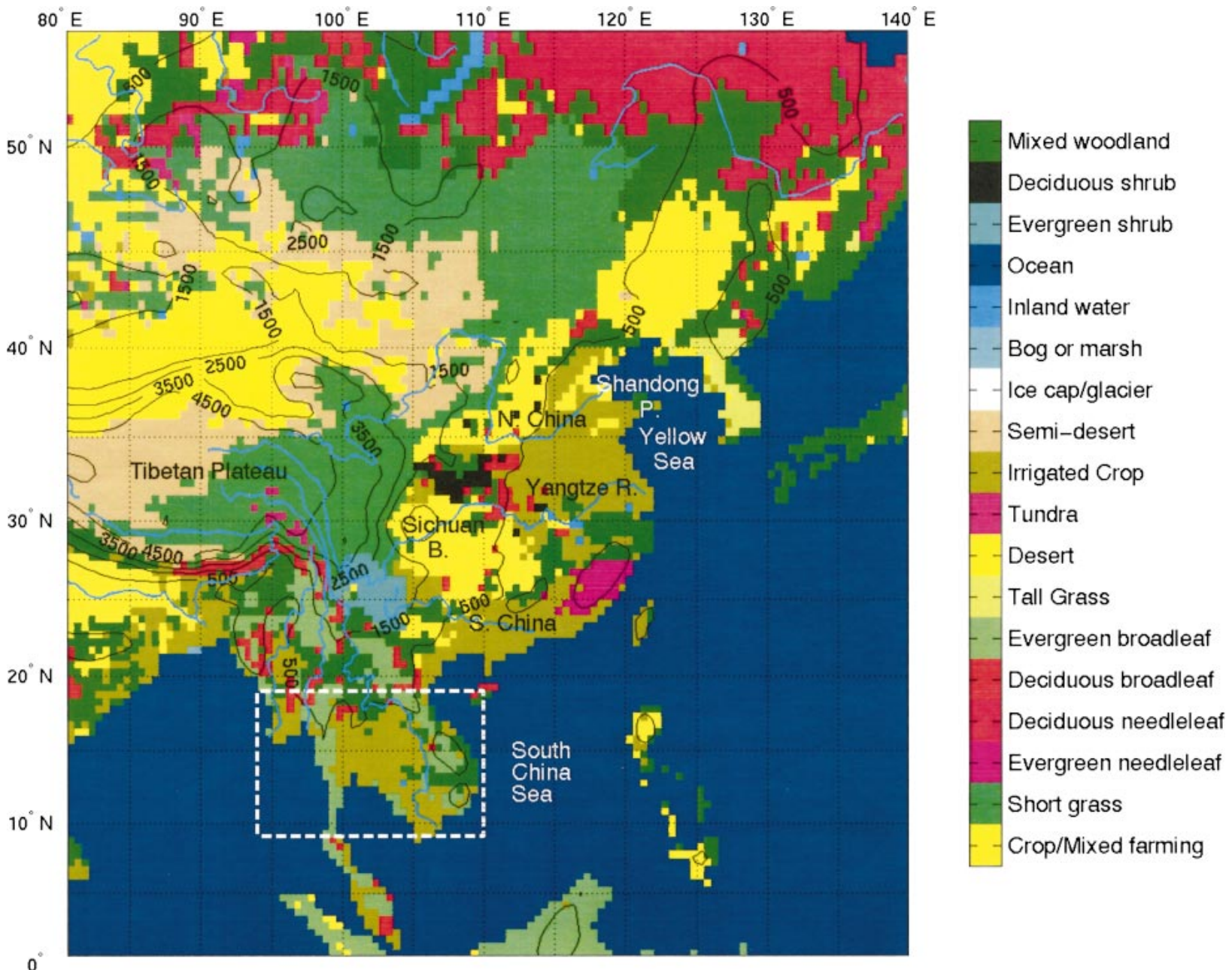

FIG. 1. BATS vegetation cover in the model domain. Contours are showing the topography. The dashed rectangle is the area where irrigated crop grid cells are replaced with evergreen broadleaf.

(e.g., Ding 1994; Ding and Liu 2001; Wang et al. 2003), we will only mention the points that may be important to understand and interpret the results of this study. Ding (1994) identifies three air currents that cause and affect monsoon processes over east Asia: the Indian monsoonal westerlies, which carry abundant moisture from the Indian Ocean; the cross-equatorial air current over northern Australia and its neighboring sea region; and the tropical western Pacific easterlies associated with the western Pacific subtropical high pressure system (WPSH). The SCS is where these air currents are usually deflected northward. The location and the strength of the WPSH play an important role in the northward redirection of the wind fields. Because the IP lies just west of the deflection area, it is usually subject only to the strong westerlies in the summer months. The onset of the monsoon rainy season occurs in early May over the IP, and it quickly extends northeastward (Wang and LinHo 2002). The withdrawal of the wet season from the IP occurs in October (Kanae et al. 2001).
Almost all of the summer rainfall over China is generated by the EASM, and the beginning and the end of the rainy season is usually marked by the onset and the withdrawal of the monsoon. The onset of the EASM is widely recognized by the appearance of the westerlies over the SCS region around mid-May. As summer monsoon develops, the primary rainbelt over east Asia advances northward. This seasonal rainbelt becomes somewhat stationary over south China, the YangtzeHuaihe River basin, and north China, respectively, during its two notable northward jumps (Ding and Liu 2001). When the monsoon rainband reaches the Yangtze-Huaihe River basin in the first half of June, it marks the beginning of the so-called mei-yu season in China (Wang and LinHo 2002). The mei-yu season, which peaks in late June, is characterized by torrential rainfall associated with the quasi-stationary mei-yu front. The withdrawal of the monsoon rainy season from China occurs in late August.

The summer of 1998 was marked with heavy rainfalls 
(a)
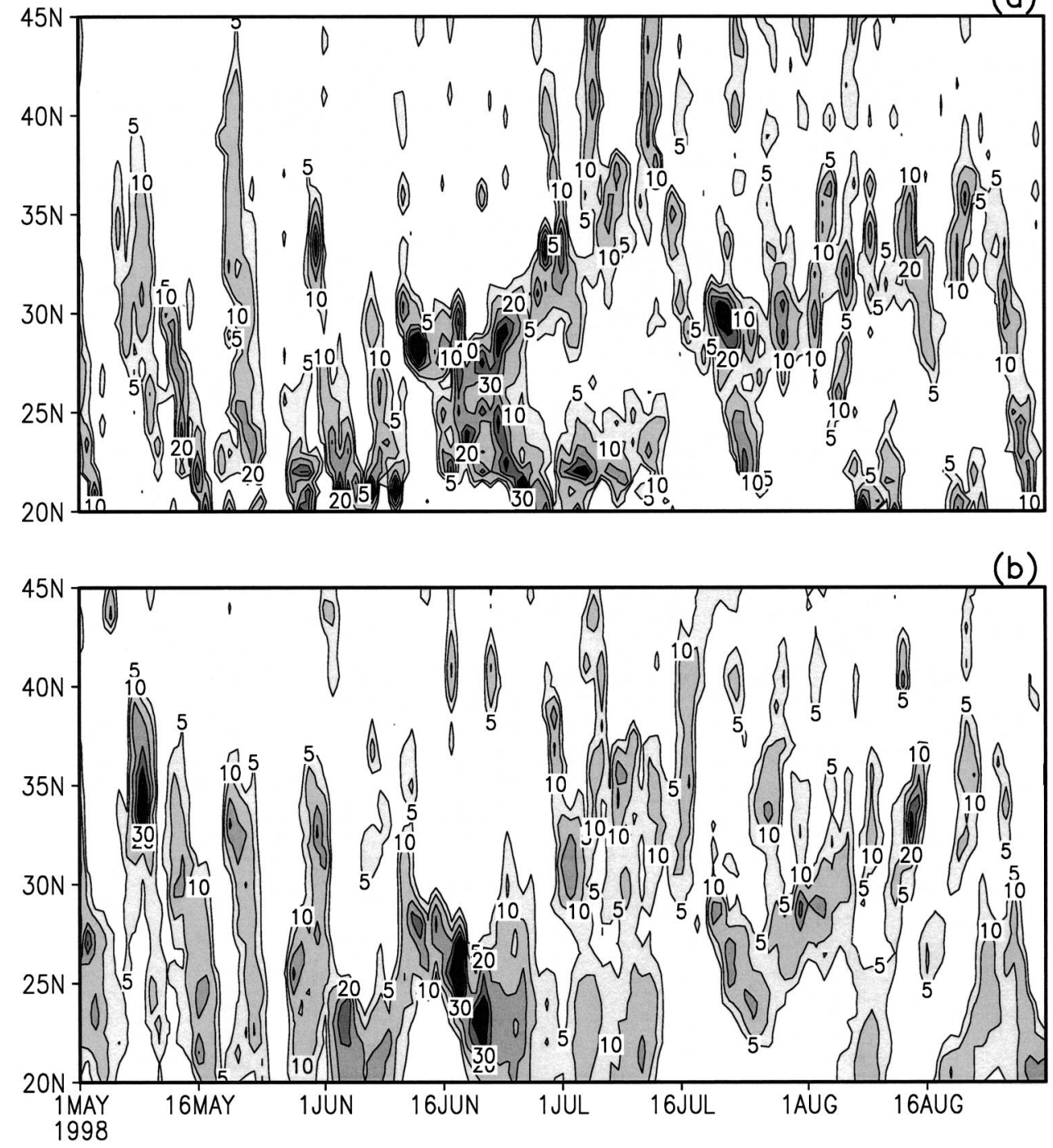

FIG. 2. Time evolution of (a) observed and (b) model-simulated (from CURRENT) rainfall averaged between $105^{\circ}$ and $120^{\circ} \mathrm{E}\left(\mathrm{mm}\right.$ day $\left.^{-1}\right)$.

that caused severe floods in the Yangtze River basin, the largest since the 1954 summer. Large economic losses in China were associated with these floods. An unusual second mei-yu period occurring in the 1998 summer (Ding and Liu 2001) was believed to increase the losses significantly. The abnormal monsoon rainfall was also related to the prolonged impact of the 1997/98 El Niño event, which was the strongest in the last century (Wang et al. 2000).

\section{Results}

\section{a. Model performance}

The performance of the model was primarily assessed through its ability to simulate spatial and temporal variations of rainfall because rainfall is a stringent criterion and the main concern in this study. A gridded version of the daily rainfall data from approximately 950 stations (most of them are in China, the Korean peninsula, Mongolia, Thailand, and Vietnam, and a few or none in the other countries in the IP) was utilized to evaluate the model simulations.

Figure 2 shows the time evolution of observed and model-simulated rainfall, averaged between $105^{\circ}$ and $120^{\circ} \mathrm{E}$. The model simulated well the majority of the precipitation events associated with both southwardpropagating cold frontal systems and the quasi-stationary mei-yu fronts. Some of the events, however, are missed or underestimated, specifically the one in late June between $27^{\circ}$ and $31^{\circ} \mathrm{N}$. The monthly statistics on average rainfall, spatial and temporal correlations, spatial standard deviations, and biases for this area are giv- 
TABLE 1. Statistics between observed and modeled rainfall for an area between $20^{\circ}-45^{\circ} \mathrm{N}$ and $105^{\circ}-120^{\circ} \mathrm{E}$. The units are all mm day ${ }^{-1}$, except for the correlations. SSD stands for "spatial standard deviation."

\begin{tabular}{|c|c|c|c|c|c|c|c|}
\hline Month & Observed rainfall & $\begin{array}{l}\text { Modeled } \\
\text { rainfall }\end{array}$ & Spatial correlation & $\begin{array}{c}\text { Temporal } \\
\text { correlation }\end{array}$ & Observed SSD & Modeled SSD & Bias \\
\hline May & 4.14 & 5.98 & 0.69 & 0.67 & 2.94 & 3.95 & 1.84 \\
\hline Jun & 5.97 & 5.45 & 0.64 & 0.61 & 6.15 & 6.41 & -0.52 \\
\hline Jul & 5.89 & 5.99 & 0.41 & 0.32 & 3.67 & 3.45 & 0.10 \\
\hline Aug & 4.21 & 4.37 & 0.55 & 0.42 & 3.03 & 2.58 & 0.16 \\
\hline
\end{tabular}

en in Table 1. The model seems to perform better in the early months (May and June) than the later months (July and August). July simulation is particularly difficult for this year (Wang et al. 2003).

Similar statistics as in Table 1 are also calculated for June-July-August (JJA) for the same area. The modelestimated rainfall is $5.27 \mathrm{~mm}_{\text {day }}{ }^{-1}$. The observed rainfall is $5.35 \mathrm{~mm} \mathrm{day}^{-1}$. Spatial and temporal correlations are 0.66 and 0.52 , respectively. Spatial standard deviations are $3.26 \mathrm{~mm} \mathrm{day}^{-1}$ for model-estimated rainfall and $2.99 \mathrm{~mm} \mathrm{day}^{-1}$ for observed rainfall. We also calculated standard deviations for both CURRENT and FOREST ensembles separately to give an indication of the degree of spread between ensemble members. They are $0.155 \mathrm{~mm} \mathrm{day}^{-1}$ for the CURRENT ensemble and $0.154 \mathrm{~mm} \mathrm{day}^{-1}$ for the FOREST ensemble.

Figure 3 gives the modeled and observed time series of the area-averaged rainfall between $12^{\circ}-20^{\circ} \mathrm{N}$ and $99^{\circ}-104^{\circ} \mathrm{E}$, which covers mainly Thailand-the IP country with most of the available data. In general, the model captures the time evolution of the rainfall. Some of the large disparities between modeled and observed rainfall could be related to the uneven representation of the station data, as well as to model's performance over a tropical region where convective precipitation is dominant. The overall performance of the model, though, is adequate to carry out a deforestation sensitivity study.

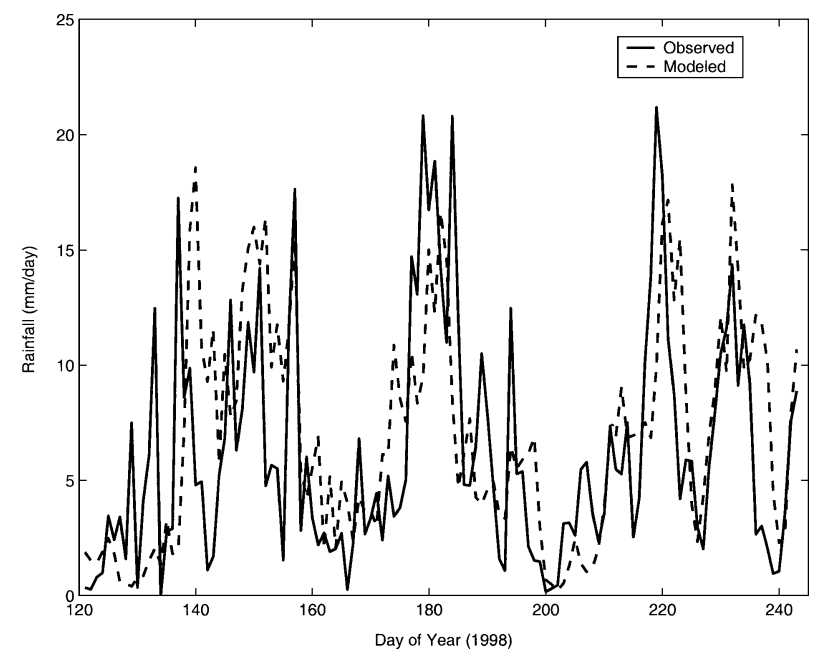

FIG. 3. Time series of observed and modeled precipitation (from CURRENT ensemble) averaged over $12^{\circ}-19^{\circ} \mathrm{N}$ and $99^{\circ}-104^{\circ} \mathrm{E}(\mathrm{mm}$ day $^{-1}$ ).

\section{b. Local changes due to deforestation}

As mentioned earlier, deforestation is expected to change the local weather and climate because it alters the exchange of energy, water vapor, and momentum between the surface and atmosphere. This section reports the changes in surface fluxes and cross sections of the atmospheric variables over the deforested areas. Hereafter, the analysis concentrates on combined JJA effects as JJA marks the mature phase of EASM.

Previous deforestation studies suggest a reduction in latent heat flux and an increase in sensible heat flux over the deforested area. The results of our modeling experiment confirm this. The latent (sensible) heat flux is reduced (increased) over the deforested area, but the magnitude of the reduction (increase) is not uniformly distributed over the whole area-the largest changes usually tending to occur upwind (not shown). As can be noticed later, the latter is related to the changes in rainfall in the IP.

Figure 4 shows, as differences between CURRENT and FOREST runs, the JJA cross sections of water vapor mixing ratio (shaded) and air temperature, vertical velocity (shaded) and zonal wind, and vertical velocity (shaded) and meridional wind. The zonal sections are based on the averages between $13^{\circ}$ and $17^{\circ} \mathrm{N}$, while the meridional sections are based on the averages between $100^{\circ}$ and $105^{\circ} \mathrm{E}$. Both cover the main deforested area in Thailand. The zonal sections show reduced humidity, increased temperature, and enhanced zonal wind at the lowest level $(950 \mathrm{mb})$ over the deforested area between $100^{\circ}$ and $106^{\circ} \mathrm{E}$. This local effect is observed up to about $850 \mathrm{mb}$, with the deepest penetration being in the upwind side. The depth of the effect gradually decreases toward the downwind side. Immediately over this surface-influenced layer lies another layer with increased humidity whose maximum is on the eastern side (Fig. 4a). The zonal wind is reduced at the western edge of this layer while increased at the eastern edge (Fig. 4c). Figure $4 \mathrm{c}$ further indicates enhanced rising motions over the deforested area in Thailand-the maximum being over the eastern portion-and increased subsidence at the eastern and western edges of this major deforested area. The increased rising motions over the deforested area reduces surface pressure and geopotential heights up to $850 \mathrm{mb}$ (not shown). The meridional section (Fig. 4b) shows a similar stratification for air temperature and humidity difference. The meridional component of the 
(a) $Q$ and $T$ averaged for $13-17^{\circ} \mathrm{N}$

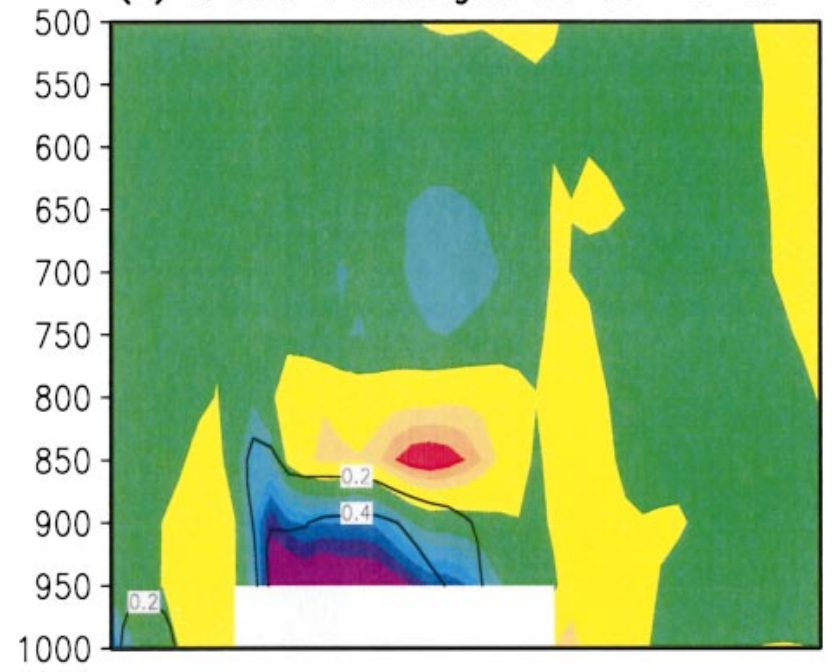

(c) $w$ and $u$ averaged for $13-17^{\circ} \mathrm{N}$

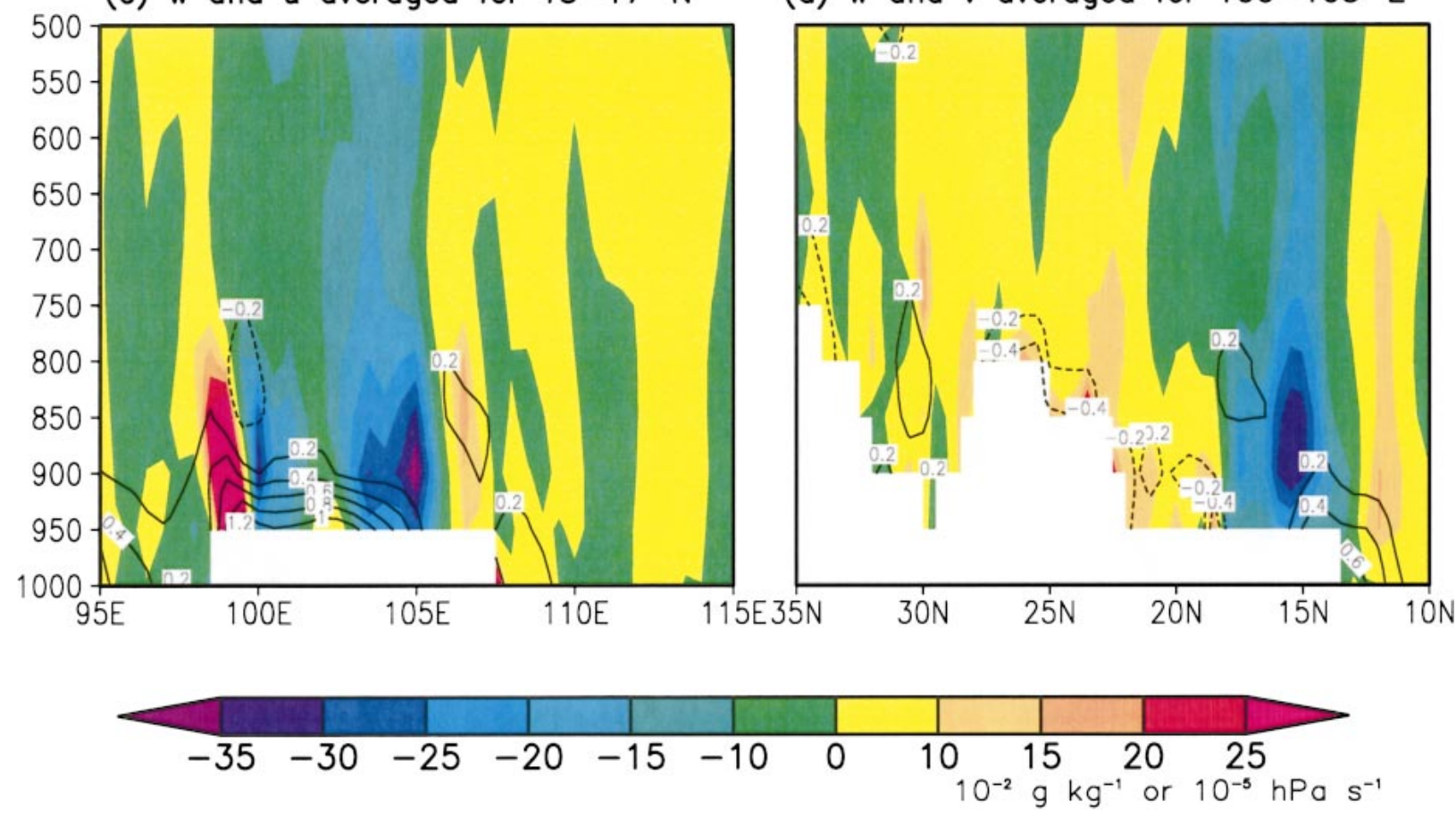

(b) $Q$ and $T$ averaged for $100-105^{\circ} \mathrm{E}$

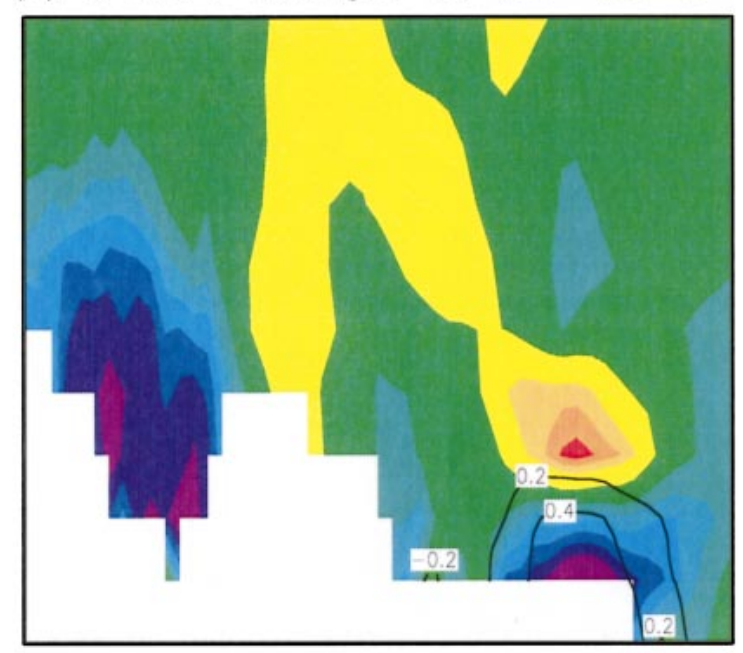

(d) $w$ and $v$ averaged for $100-105^{\circ} \mathrm{E}$

FIG. 4. (a) Zonal section of change in water vapor mixing ratio ( $\mathrm{g} \mathrm{kg}^{-1}$; shaded) and air temperature (K; contour); (b) same as in (a), but for a meridional section; (c) zonal section of change in vertical velocity ( $\mathrm{hPa} \mathrm{s}^{-1}$; shaded) and zonal wind (m s ${ }^{-1}$; contour); and (d) meridional section of change in vertical velocity ( $\mathrm{hPa} \mathrm{s}^{-1}$; shaded) and meridional winds ( $\mathrm{m} \mathrm{s}^{-1}$; contour). Changes are calculated as CURRENT FOREST. The zonal sections [(a) and (c)] are based on averages in latitudes between $13^{\circ}$ and $17^{\circ} \mathrm{N}$, and the meridional sections [(b) and (d)] are based on averages in longitudes between $100^{\circ}$ and $105^{\circ} \mathrm{E}$.

wind (Fig. 4d), which is southerly over the peninsula, is enhanced over the southern portions of the peninsula while it is weakened north of the deforested area and southeastern skirt of the Tibetan Plateau (TP). Subsidence is enhanced both north and south of the deforested area. Apart from these changes in the vicinity of the peninsula, a substantial reduction in air humidity and an increase in the meridional wind are seen around $30^{\circ} \mathrm{N}$.
In conclusion, the deforestation in the IP causes significant changes in the local atmosphere. The model results indicate that clearing the forest alters the surface energy and water balance in such a way that the surface becomes drier and warmer. A drier and warmer surface enhances the rising motions, increasing the depth of the planetary boundary layer. (Later, we will see that the increased cyclonic vorticity over the deforested areas 


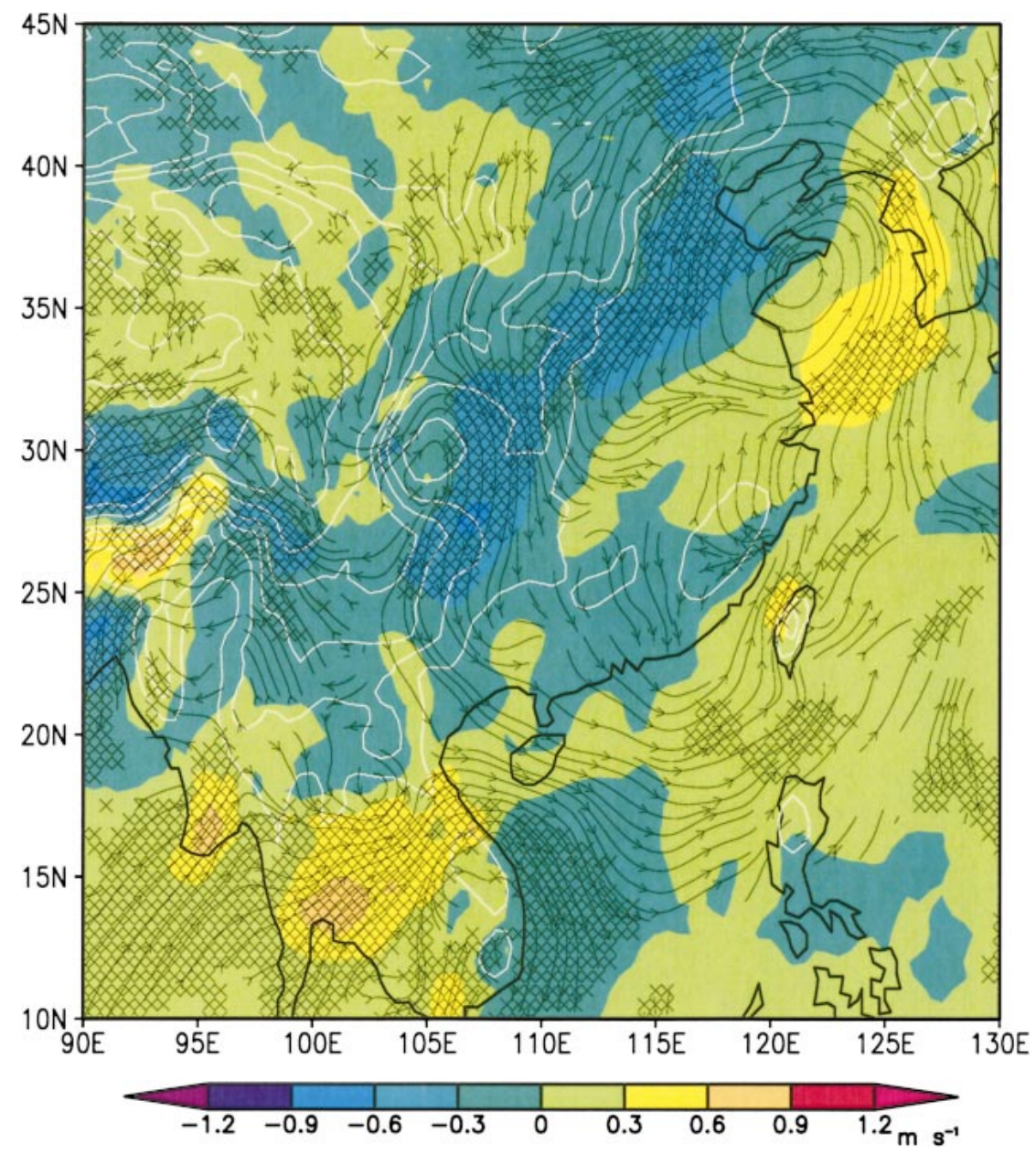

FIG. 5. JJA difference in the fields of wind (as streamlines) and their magnitude $\left(\mathrm{m} \mathrm{s}^{-1}\right.$; shaded) averaged for the lowest nine sigma levels (from surface up to about $1.5 \mathrm{~km}$ ). The hatching is for statistically significant areas at $90 \%$ confidence level. The contours are showing the topography (at the 500, 1000, 1500, 2000, 3000, 4000, and $5000 \mathrm{~m}$ heights).

also enhances the rising motions.) It could be argued that the deepened planetary boundary layer shifted the moist flow from the Bay of Bengal (BOB) upward over the deforested area. This would explain the increase in moisture at $800-850 \mathrm{mb}$.

\section{c. Large-scale circulation changes}

The previous section reported some significant changes in the atmospheric variables over the deforested area. Here, we investigate whether/how these changes affect the atmosphere in the vicinity and beyond. Figure 5 shows the effects of deforestation (CURRENT - FOREST) on the wind fields (as streamlines) and their magnitude (shaded) averaged over the first nine sigma levels from the surface over an area between $10^{\circ}-45^{\circ} \mathrm{N}$ and $90^{\circ}-130^{\circ} \mathrm{E}$ (note that these sigma levels follow topography; over lowlands and seas, they extend from surface to about a $1.5-\mathrm{km}$ height). The hatching indicates areas in which wind magnitude changed significantly (at the
90\% confidence level), and the contours show the topography to help identify the location of the changes and the possible contribution of topography to these changes. Similarly, Fig. 6 shows the change in the water vapor mixing ratio.

The westerly and southwesterly flow over the deforested area is significantly strengthened by deforestation (Fig. 5). The streamlines indicate that the reduced friction at the surface of the deforested areas in Thailand and Cambodia makes these areas favorable paths for the monsoonal flow, especially for the flow to the northwest. This increases cyclonic vorticity over the northern and western portions of these areas. The deflection of the airflow in the northwest of the deforested area can even weaken the winds over the slopes immediately north of the deforested area in Thailand. The water vapor mixing ratio (Fig. 6) is reduced over the whole deforested area, but the largest changes occur in the western parts. (Because the eighth and ninth sigma levels pass through the increased humidity layer whose maximum occurs 


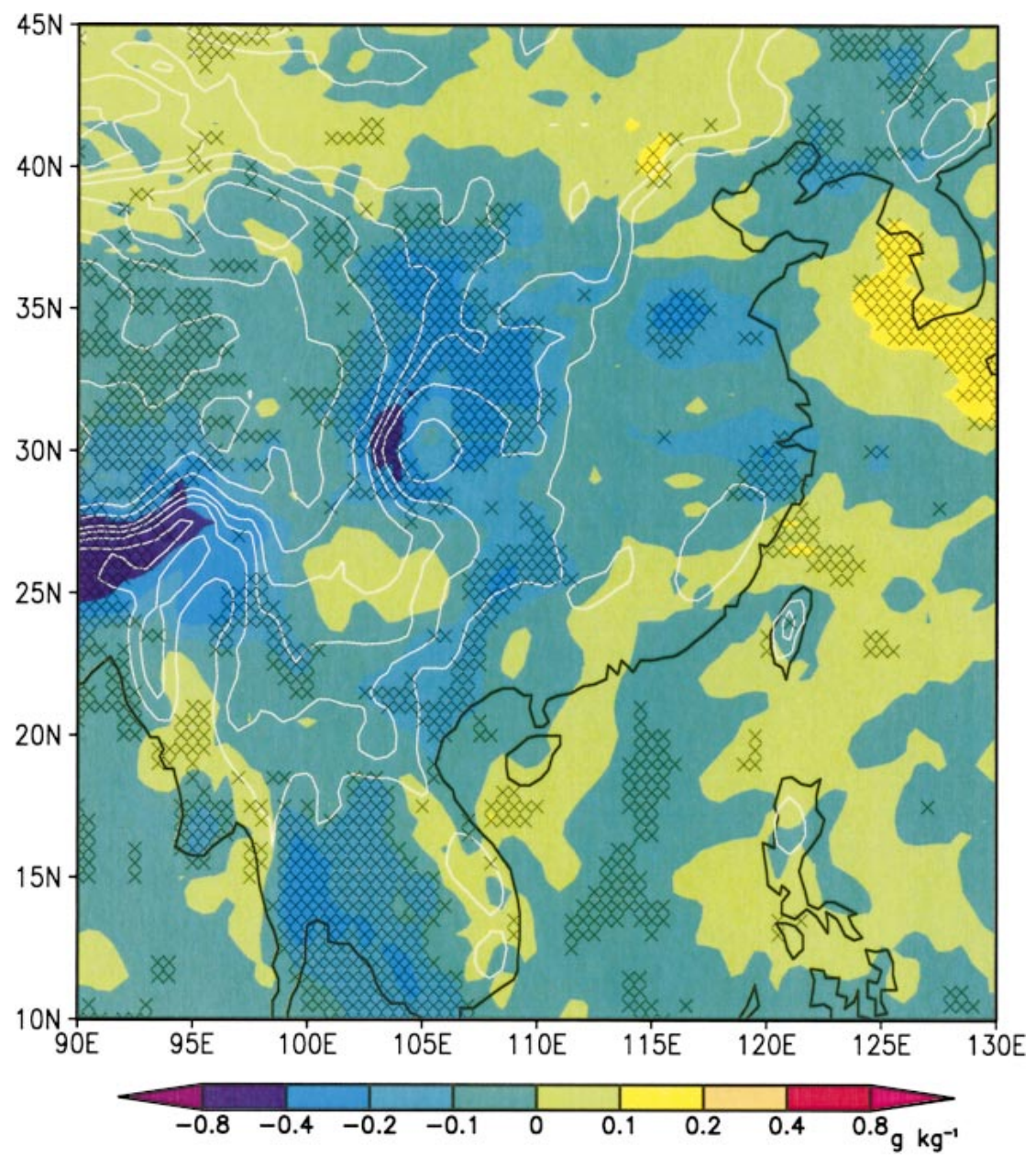

FIG. 6. JJA difference in the water vapor mixing ratio $\left(\mathrm{g} \mathrm{kg}^{-1}\right.$; shaded) averaged for the lowest nine sigma levels. The hatching is for statistically significant areas at $90 \%$ confidence level. The contours are showing the topography (at the 500, 1000, 1500, 2000, 3000, 4000, and $5000 \mathrm{~m}$ heights).

downstream over the deforested area, averaging over all nine sigma levels decreases downstream change in the water vapor mixing ratio.) The winds over the northern parts of the SCS are deflected eastward and become stronger due to the greater influence of the westerly flow there. The streamlines in that region indicate increased cyclonic vorticity as well. The southerly flow east of the IP becomes significantly weaker. It seems that the increase in the westerly flow over the IP is partly balanced by the decrease in this southerly flow. In addition to these changes over and around the test area, the speed of the southerly flow over the east flank of the TP is significantly reduced. The cyclone-like anomaly in the wind fields over the Shandong Peninsula and the Yellow Sea works to enhance monsoonal flow in the east, while weakening it in the west. Over east China and neighboring seas, the change in the wind fields at $850 \mathrm{mb}$ (not shown) reveals a similar pattern to that in Fig. 5. The mixing ratio difference (Fig. 6) indicates significant reductions in moisture over the eastern flanks of the TP.
This may imply that the drier air of the TP moves over these areas and/or the moisture transport toward these areas weakens. We can also see some significant differences in wind strength south of the TP, that is, over Bangladesh and northeast of India. The mixing ratio decreases around the southern edge of the TP, indicating less moisture transport to the area.

Combining the information in these figures with that in the previous figures, we may speculate on a mechanism that explains how deforestation affects the atmospheric large-scale circulation in this particular case. Deforestation reduces the roughness of the surface, thus, reducing surface friction and enhancing winds. This process makes the westerlies stronger over the deforested areas to about the $850-900-\mathrm{mb}$ levels. The stronger westerlies meet a southerly flow over the SCS that is often associated with the cross-equatorial airflow between Java and Sumatra, or with the southern flank of the subtropical high over the western Pacific (Ding 1994). When the westerly flow becomes stronger over 
the SCS this southerly flow becomes weaker. The stronger influence of the westerlies in northern SCS deflects winds toward the east. This clockwise turn in the wind direction in northern SCS weakens the airflow over the land area immediately to the north (southeastern China). The deforestation in Thailand has additional local impact on the atmosphere: it weakens the monsoonal flow to the north of the area by deflecting its course. The changes in the atmospheric circulation over the area between BOB and the TP, caused probably by the deforested area in Myanmar, weakens the monsoonal airflow passing over the southeastern skirt of the TP. These last two processes weaken the monsoonal flow over the eastern flank of the TP. In conclusion, the atmospheric processes as a result of deforestation in the IP result in an east Asia monsoon circulation that is weaker in the west and stronger in the east. The analysis suggests that deforestation in the IP can have both significant local and far-reaching effects on the large-scale circulation.

\section{d. Changes in precipitation}

\section{1) Spatial changes}

Figure 7 illustrates the spatial distribution of the absolute difference in rainfall (shaded) between CURRENT and FOREST ensemble means. Regions where statistical significance reaches the $90 \%$ confidence level are hatched. Rainfall increases significantly on the downwind side of the deforested areas. Significant, coherent reductions also occur upwind of the deforested areas. It is worth mentioning that this dipole pattern occurs not only for the relatively large deforested areas of Thailand and Cambodia, but also for the comparatively small deforested area of Myanmar. This figure further shows a pattern with wetter and drier bands that elongate from the southwest to northeast over eastern China and neighboring seas. Downwind of the IP lies one of the wetter bands that extends northeastward, following the southeastern coast of China. To the northwest, a band that indicates drying is followed by one that indicates wetting, but the changes in these bands are somewhat patchy. The significance test indicates that some of these changes are statistically significant, for example, those over the Yangtze-Huaihe River basin around $115^{\circ} \mathrm{E}$. These bands of rainfall change form a sandwich-type pattern over eastern China. Some studies (e.g., Xue 1996) report such a pattern (drying in north and south China, and wetting in the Yangtze River basin) in the observed JJA rainfall difference between the 1980s and 1950s, and seek a relation between the changes and desertification in northern China and Mongolia. The sensitivity experiment of Xue (1996) results in a similar pattern but the aerial coverage and the locations of the changes are largely different from those observed. One exception is the drying area in north China that is well produced by his desertification experiment. The present study suggests that a sensitivity experiment for deforestation in the IP can result in a similar (sandwich type) pattern in eastern China, though the drying area in north China is less pronounced, compared to the observations and the modeling results of Xue (1996). This implies that desertification in northern China and Mongolia could be another important factor that causes changes in the rainfall patterns in eastern China. We have to acknowledge that some other factors, such as the increase in greenhouse gasses, sulfate aerosols, black carbon, etc., might also play important roles in the climate of China.

The rainfall change over the IP can be explained by changes in vertical velocity and water vapor mixing ratio given in Fig. 4. The area of increased rainfall, for instance, lies exactly under the air with increased rising motions and increased humidity at about $850 \mathrm{mb}$. On the other hand, the area of drying in the west seems to be related to enhanced subsidence and deep penetration of surface dry air in the western part of the peninsula. The changes in the large-scale atmospheric circulation seen in Fig. 5 could explain many of the changes in rainfall in eastern China and neighboring seas. The increased rainfall in the northern SCS corresponds well with the increased cyclonic vorticity and with enhanced westerlies. The weakening of the moist monsoonal flow in southeastern China seems to be the reason for decreased rainfall in this area. The increased rainfall around the Yangtze-Huaihe basin and Yellow Sea region is related to the increased cyclonic vorticity there. In fact, the significance test for vorticity (not shown) indicates that the cyclonic vorticity is increased significantly on a band there that coincides well with the band where rainfall is increased. The reductions in rainfall around Sichuan basin (around $30^{\circ} \mathrm{N}$ and $105^{\circ} \mathrm{E}$ ) should be a consequence of decreased humidity as well as increased anticyclonic vorticity there.

In summary, deforestation in the IP can have significant remote as well as local effects on regional precipitation by influencing the monsoonal flow, the main moisture supplier to higher latitudes in summer.

\section{2) Changes in RAinfall FREQUenCy}

Not only the changes in total rainfall, but also the changes in the characteristics of the rainfall are important because they are used for hydrologic purposes. For this reason, a rainfall frequency analysis based on model outputs is included in this section. Figure 8 shows the frequency difference (days month ${ }^{-1}$ ) between CURRENT and FOREST runs for the daily rainfall larger than $16 \mathrm{~mm}$ (Fig. 8a) and less than $4 \mathrm{~mm}$ (Fig. 8b). In general, the number of days with rainfall over $16 \mathrm{~mm}$ increases in areas where total rainfall increases (see Fig. 7 ), while the opposite is the case where total rainfall decreases (the spatial correlation is 0.62 over this domain). Specifically, the frequency of daily rainfall over $16 \mathrm{~mm}$ increases over most of the IP, parts of the Yangtze River basin, and northwest of the Korean Peninsula; the 


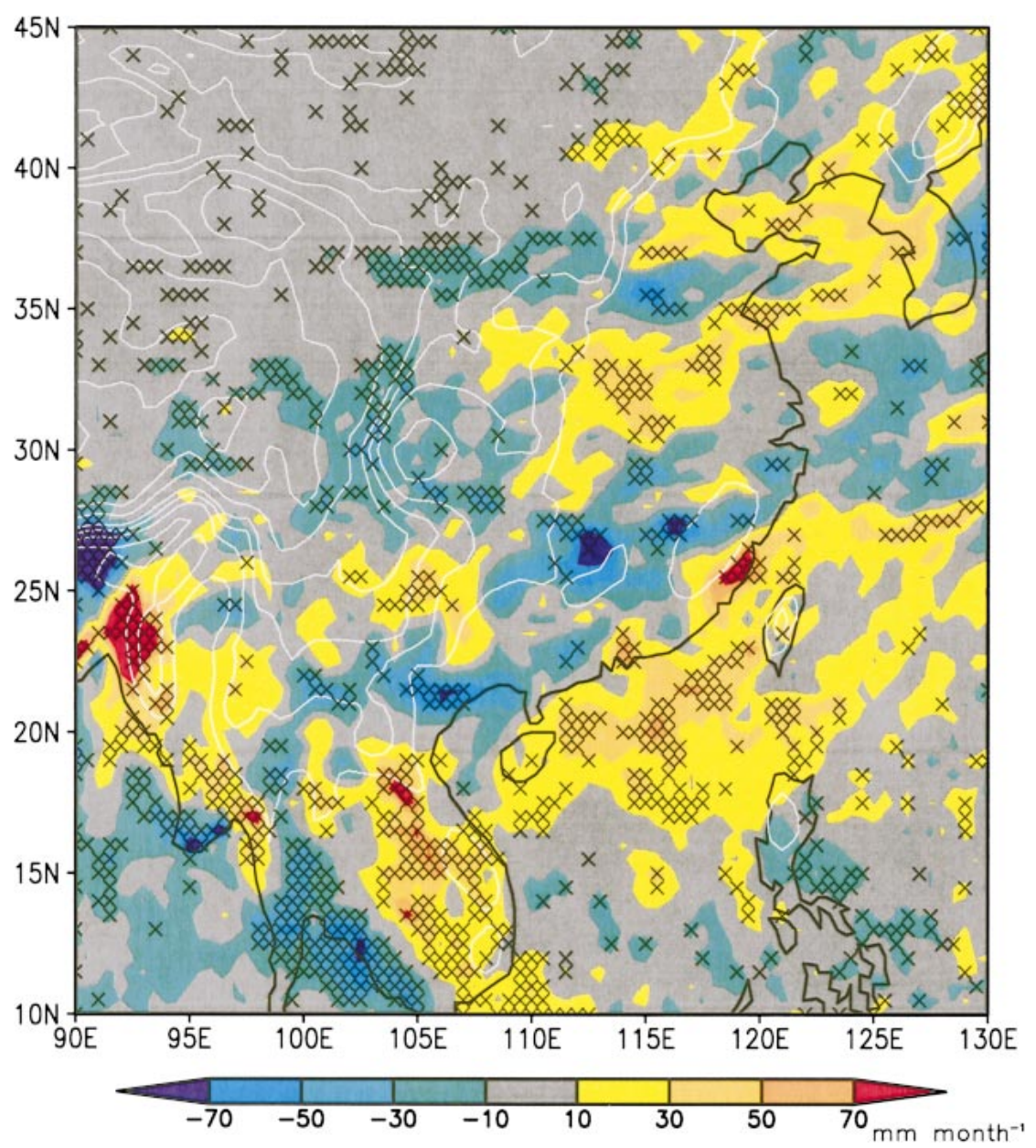

FIG. 7. Spatial distribution of the absolute ( $\mathrm{mm} \mathrm{month}{ }^{-1}$; shaded) rainfall change in JJA. The hatching is for statistically significant areas at $90 \%$ confidence level. The contours are showing the topography (at the 500, 1000, 1500, 2000, 3000, 4000, and $5000 \mathrm{~m}$ heights).

increase is usually $1-3$ days. The frequency of rainfall below $4 \mathrm{~mm}$ increases upwind of the deforested areas and over the southeastern and eastern flanks of the TP. The frequency decreased in parts of Myanmar, downwind of the deforested area in Thailand, and over parts of Yangtze River basin. The spatial correlation between the frequency difference of daily rainfall below $4 \mathrm{~mm}$ and absolute rainfall difference is about -0.41 . In conclusion, the model results suggest that deforestation in the IP could cause some remarkable changes in the frequency distribution of rainfall, and the changes in the frequency of high rainfall account for a large fraction of the changes in the total rainfall.

\section{3) OBSERVED TRENDS}

The sole purpose of this section is to seek qualitative evidence in the observed rainfall trends about whether the deforestation in the IP could be a factor causing changes in regional climate. The result of this section should, therefore, be treated as a precursor for further research in exploring the true nature of the relationship between the Indochina deforestation and changes in regional climate.

We used the University of Delaware $0.5^{\circ}$-grid monthly precipitation data, which covers the time from January 1950 to December 1996. A linear regression technique was used to obtain the slopes of rainfall trends at each grid point over land. (No data are available over oceans and seas.) A negative value indicates a decreasing trend, a positive value an increasing trend. To assess the effect of the recent years on the trends, a similar analysis was also performed on station data from China (not shown), which includes recent data (until 2001). Both gridded and station distributions are found to be in broad qualitative agreement, with some slight differences that will be mentioned later.

Figure 9 shows the distribution of the slopes of the trends for JJA. As in the modeled rainfall difference, a dipole with wetting trends downstream and drying trends upstream appears in the IP, but only in the southern parts. Unlike the model's extended dipole toward 

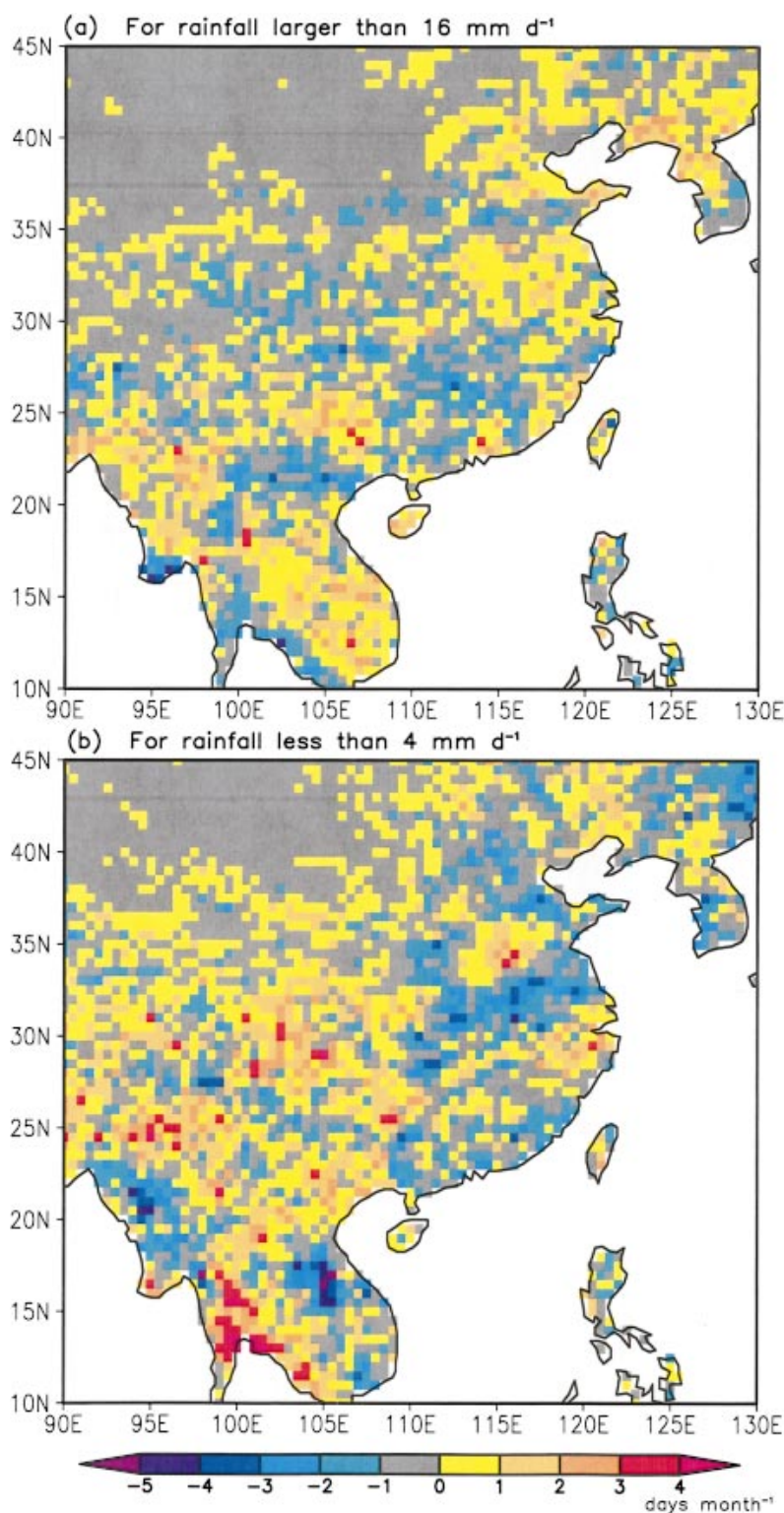

FIG. 8. JJA frequency change (days month ${ }^{-1}$ ) for the daily rainfall (a) larger than $16 \mathrm{~mm}$ and (b) less than $4 \mathrm{~mm}$.

the higher latitudes in the IP, observations indicate an area with wetting trends in the middle (the main deforested area in Thailand) surrounded by areas with drying trends. There is an area with a strong wetting trend over the southern parts of Myanmar (northwest coast of the peninsula). East of this is an area that has become much drier and that extends toward north and northwest covering the south and southeastern skirts of the TP. The model results show a similar tendency, but not as clearly, perhaps because of limitations in the experimental design. In our experiment, we have taken into account only the deforested areas below $19^{\circ} \mathrm{N}$ latitude, but there is another deforested area in Myanmar north of this line. Therefore, the effect of deforestation in this

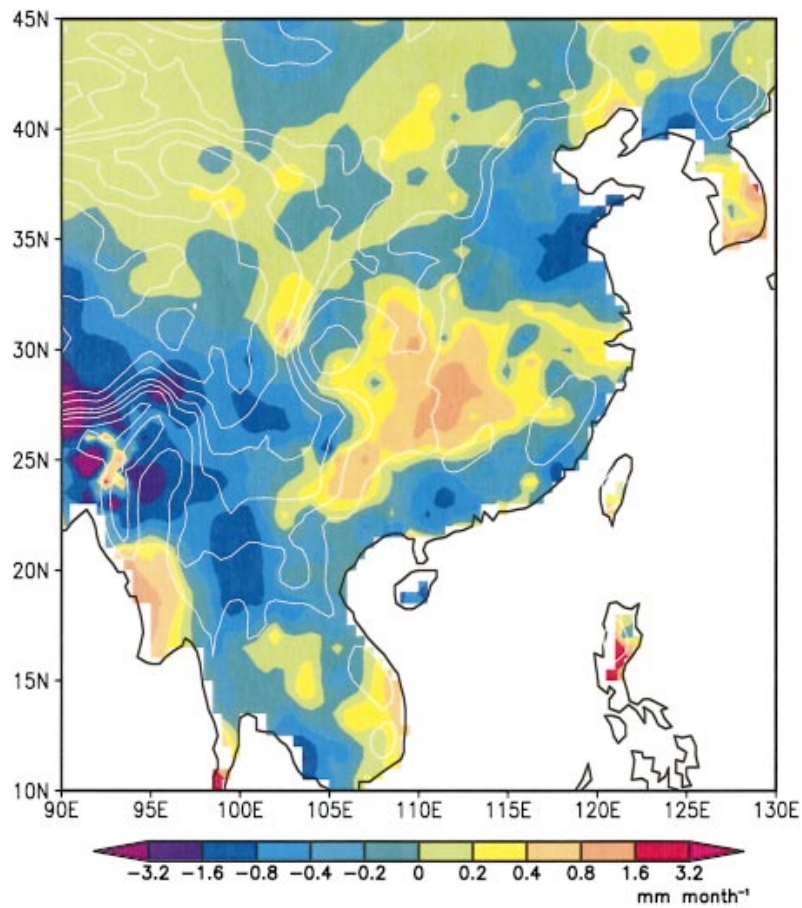

FIG. 9. Spatial distribution of the slopes $\left(\mathrm{mm} \mathrm{month}^{-1}\right)$ in JJA that are calculated for each grid from observed rainfall data available between 1950 and 1996. The contours are showing the topography (at the 500, 1000, 1500, 2000, 3000, 4000, and $5000 \mathrm{~m}$ heights).

area is not accounted for in this experiment. Our simulation results suggest that the disturbance caused by the deforestation in the peninsula reduces moisture transport toward the TP, which then reduces rainfall over the surrounding areas (see Figs. 5, 6, and 7). Based on the observed trends, it can, therefore, be argued that the deforested area not included in our experiment is intensifying this phenomenon. This may also be the reason behind stronger drying around $20^{\circ} \mathrm{N}$ and $100^{\circ} \mathrm{E}$, compared to the modeled drying. Most likely, the deforestation in Myanmar, while increasing the local precipitation, has created a rain shadow to the east. The deforestation in Thailand (central peninsula) probably contributes further to the drying in this area because it attracts the air over the slopes in the north. The deforestation in Myanmar certainly needs further and separate investigation because it may be an important factor affecting the rainfall in Bangladesh and northeastern India.

Observations show a further drying band in southeastern China that resembles the modeled one. Longerterm station data, however, suggest that this area with drying trends is confined to a rather small region in southeastern China. Furthermore, the stations at the southeast shoreline all indicate positive trends. As discussed earlier, the model results show a widespread increase in precipitation along the southeastern coasts of China and in the northern parts of the SCS. Because there are no long-term rainfall measurements over the 
SCS, it is difficult to evaluate this result with observations, but it could be argued that the observed positive trends along the shoreline may be an indication of positive trends over the north SCS. In fact, the trends based on CMAP data, albeit comparatively short term (23 yr), indicate wetting trends in north SCS.

In observations, there is a large area with a wetting pattern in the eastern China. The wetting trends based on station data suggest a similar pattern to this, the maximum center, however, being shifted eastward. The model results show such a wetting pattern for similar areas, but the pattern is more patchy and shifted slightly northward. The patchiness and the northward shift could be related to differences in the large-scale circulation between 1998 and the average of 1950-96. A drying pattern in the north extends from the TP to the Yellow Sea, but the maxima occur at the ends, that is, the Shandong Peninsula and eastern flank of the TP. The model results also indicate decreased rainfall at these locations, but the extents of these drying patterns are somewhat different from those observed. The drying area around Shandong Peninsula appears considerably smaller in the model results. Other landscape changes in and around China are known to have regional effects. As mentioned earlier, desertification in Mongolia and in northern China is another important factor affecting this region (e.g., Xue 1996). The experiments of Xue (1996), for instance, produced a larger drying area in northeastern China.

The above comparison between modeled rainfall changes and the observed rainfall trends suggests that the deforestation in the IP might be an important factor causing changes in the climate of the region. A thorough investigation involving multiyear (at least $10 \mathrm{yr}$ ) simulations will be invaluable to understand the true nature of the relationship between the deforestation in the IP and the climate change in the region.

\section{Summary and conclusions}

It is broadly recognized that the landscape change can have significant impact on the overlying atmosphere because it alters the surface-atmosphere interaction processes. The degree of impact is, however, a complicated issue because it depends on several factors, such as the characteristics and the extent of the surface change. Deforestation is one type of landscape change, and has been widely studied in Amazonia, which has the largest rain forest on the earth. Tropical southeast Asia had considerable rain forests in the past, but was subjected to widespread clearing under the population pressure during the last century. The rate of deforestation in the IP dramatically increased in the second half of the twentieth century. The fact that the peninsula lies under the main flow path of the Indian monsoonal westerlies, whose moisture is vital for China and adjacent countries, makes it extremely important to assess the impact of deforestation in the IP on this air current. A numerical experiment has been conducted, therefore, to investigate the impact of deforestation in the peninsula on the east Asian summer monsoon, in general, and its rainfall, in particular. The results from this experiment are summarized as follows:

- The results of the modeling experiment suggest that the deforestation in the IP increases local wind speed and temperature and decreases the water vapor mixing ratio. The direct surface effect due to deforestation is observed up to about $850 \mathrm{mb}$ over the main deforested area in Thailand. In addition, the deforestation tends to enhance rising motions, and, hence, to reduce surface pressure and geopotential heights up to $850 \mathrm{mb}$. The enhanced rising motions whose maximum occur downwind causes the moist air of the prevailing flow to reach higher levels in the atmosphere. Moreover, subsidence increases over the areas around the upwind edge of the deforested areas. These local changes tend to increase rainfall downwind and decrease it upwind over the Indochina Peninsula.

- The deforestation displays also far-reaching effects on the east Asian summer monsoon. It weakens monsoonal flow in the eastern flank of the Tibetan plateau and strengthens toward the western Pacific subtropical high. The remote effects are marked by sandwich-type drier and wetter bands that are elongated along the main flow path of the EASM, that is, from the southwest to northeast. The band downwind of the deforested area is usually wetter, while the one immediately northwest of it is drier.

- This study further reveals that not only the total rainfall but also the rainfall frequency is changed. Based on modeled daily data, the frequency of high (low) rainfall increases (decreases) in regions of increased (decreased) total rainfall. In general, high spatial correlations are found between changes in the frequency of high-rainfall days and changes in total rainfall.

- A comparison of the modeled changes with the observed rainfall trends suggests that the deforestation in the Indochina Peninsula could be one of the major factors causing changes in the climate of the region. Long-term simulations are necessary to investigate the true nature of the relationship between the deforestation in the Indochina Peninsula and regional climate change.

A possible mechanism explaining how deforestation in the Indochina Peninsula may have far-reaching effects is the following: It is evident from the wind fields of the lowest $1.5 \mathrm{~km}$ of the atmosphere that the monsoonal flow is enhanced over and downwind of the deforested area, while it is weakened over the slopes to the north. The weakening is most likely related to both circulation changes in the north of the Bay of Bengal due to deforestation in Myanmar and to the increased vorticity over northern parts of the deforested area in Thailand. The positive vorticity increases the upward motion, which, then, attracts air from the Tibetan Plateau and weakens the moist monsoonal flow to the north of de- 
forested area. The strengthening of the monsoonal westerlies over the deforested areas is due to reduced surface roughness. These westerlies meet southerly winds over northern South China Sea; therefore, as the westerlies become stronger the southerly winds become weaker. The stronger influence of the westerlies over the northern parts of the South China Sea increases wind strength, deflecting the winds eastward. This, in turn, weakens the monsoonal flow over southeastern China. In conclusion, the strengthening of the monsoonal flow over the deforested areas and its weakening in the north results in a weaker monsoon flow in the west and a stronger flow in the east over eastern China and neighboring seas. These changes in the monsoonal flow, which is the main moisture supplier for China in summer, and the changes in the vorticity fields are the likely reasons behind the changes in rainfall patterns over China and neighboring seas.

As mentioned earlier, the location and the strength of the western Pacific subtropical high plays an important role in deflecting the monsoonal westerlies toward eastern China. In 1998 summer, the western Pacific subtropical high assumed significant shifts toward the west and north and became relatively strong over the South China Sea (Wang et al. 2000). This diverted more monsoonal flow toward eastern China. Given the above mechanism, this anomalous condition might have caused northward shifts in the rainfall patterns compared to those in the observed trends. In fact, if the individual months are examined (not shown), it could be seen that similar patterns in the large-scale circulation changes over eastern China and neighboring seas are shifted northwestward from June to August as the influence of the western Pacific subtropical high over eastern China increases.

Acknowledgments. Primary support for this study is provided by the Frontier Research System for Global Change. Bin Wang acknowledges the support from NSF Award N0 AM73023. The University of Delaware precipitation dataset was provided by the NOAA-CIRES Climate Diagnostics Center, Boulder, Colorado, from their Web site (online at http://www.cdc.noaa.gov/.) We appreciate the editorial assistance provided by Gisela E. Speidel, and helpful comments of two anonymous reviewers.

\section{REFERENCES}

Chen, T.-C., J. Yoon, K. J. S. Croix, and E. S. Takle, 2001: Suppressing impacts of the Amazonian deforestation by the global circulation change. Bull. Amer. Meteor. Soc., 82, 2209-2216.

Chu, P.-S., Z.-P. Yu, and S. Hastenrath, 1994: Detecting climate change concurrent with deforestation in the Amazon basin: Which way has it gone? Bull. Amer. Meteor. Soc., 75, 579-583.

Detering, H. W., and D. Etling, 1985: Application of the E- $\varepsilon$ turbulence model to the atmospheric boundary layer. Bound.-Layer Meteor., 33, 113-133.

Dickinson, R. E., and A. Henderson-Sellers, 1988: Modeling tropical deforestation: A study of GCM land-surface parameterization. Quart. J. Roy. Meteor. Soc., 114, 439-462.

, — - and P. J. Kennedy, 1993: Biosphere-Atmosphere Transfer Scheme (BATS) version le as coupled to the NCAR community climate model. NCAR Tech. Note NCAR/TN-378+STR, 72 pp.

Ding, Y., 1994: Monsoons over China. Kluwer Academic Publishers, 419 pp.

, and Y. Liu, 2001: Onset and the evolution of the summer monsoon over the South China Sea during SCSMEX Field Experiment I 1998. J. Meteor. Soc. Japan, 79, 255-276.

Easterling, D. R., T. R. Karl, K. P. Gallo, D. A. Robinson, K. E. Trenberth, and A. Dai, 2000: Observed climate variability and change of relevance to the biosphere. J. Geophys. Res., 105 (D15), 20 101-20 114.

Edwards, J. M., and A. Slingo, 1996: Studies with a flexible new radiation code. I: Choosing a configuration for a large-scale model. Quart. J. Roy. Meteor. Soc., 122, 689-719.

Gash, J. H. C., C. A. Nobre, J. M. Roberts, and R. L. Victoria, 1996: An overview of ABRACOS. Amazonian Deforestation and Climate, J. H. C. Gash et al., Eds., John Wiley and Sons.

Giambelluca, T. W., J. Fox, S. Yarnasarn, P. Onibutr, and M. A. Nullet, 1999: Dry-season radiation balance of land covers replacing forest in northern Thailand. Agric. For. Meteor., 95, 53-65.

Hahmann, A. N., and R. E. Dickinson, 1997: RCCM2-BATS model over tropical South America: Applications to tropical deforestation. J. Climate, 10, 1944-1964.

Henderson-Sellers, A., R. E. Dickinson, T. B. Durbidge, P. J. Kennedy, K. McGuffie, and A. J. Pitman, 1993: Tropical deforestation: Modeling local- to regional-scale climate change. J. Geophys. Res., 98, 7289-7315.

Kanae, S., T. Oki, and K. Musiake, 2001: Impact of deforestation on regional precipitation over the Indochina Peninsula. J. Hydrometeor., 2, 51-70.

Lean, J., and D. A. Rowntree, 1993: A GCM simulation of the impact of Amazonian deforestation on climate using an improved canopy representation. Quart. J. Roy. Meteor. Soc., 119, 509-530.

_ - C. B. Bunton, C. A. Nobre, and P. R. Rowntree, 1996: The simulated impact of Amazonian deforestation on climate using measured ABRACOS vegetation characteristics. Amazonian Deforestation and Climate, J. H. C. Gash et al., Eds., John Wiley and Sons, 549-576.

McGuffie, K., A. Henderson-Sellers, H. Zhang, T. B. Durbidge, and A. J. Pitman, 1995: Global climate sensitivity to tropical deforestation. Global Planet. Change, 10, 97-128.

Nobre, C. A., P. J. Sellers, and J. Shukla, 1991: Amazonian deforestation and regional climate change. J. Climate, 4, 957-988.

Nordeng, T. E., 1995: Extended versions of the convective parameterization scheme at ECMWF and their impact on the mean and transient activity of the model in the Tropics. ECMWF Research Department Tech. Memo. 206, 41 pp. [Available from European Centre for Medium-Range Weather Forecasts, Shinfield Park, Reading, RG2 9AX, United Kingdom.]

Pielke, R. A., Sr., 2001: Influence of the spatial distribution of vegetation and soils on the prediction of cumulus convective rainfall. Rev. Geophys., 39, 151-177.

Polcher, J., and K. Laval, 1994: The impact of African and Amazonian deforestation on tropical climate. J. Hydrol., 155, 389-405.

Reynolds, R. W., and T. M. Smith, 1994: Improved global sea surface temperature analyses using optimum interpolation. J. Climate, 7, 929-948.

Sellers, P. J., J. W. Shuttleworth, I. L. Dorman, A. Dalcher, and J. M. Roberts, 1989: Calibrating the simple biosphere model ( $\mathrm{SiB})$ for Amazonian tropical forest using field and remote sensing data. Part I: Average calibration with field data. J. Appl. Meteor., 28, 727-759.

Sen, O. L., L. A. Bastidas, W. J. Shuttleworth, Z.-L. Yang, H. V. Gupta, and S. Sorooshian, 2001: Impact of field-calibrated vegetation parameters on GCM climate simulations. Quart. J. Roy. Meteor. Soc., 127, 1199-1223.

Shuttleworth, W. J., J. H. C. Gash, J. M. Roberts, C. A. Nobre, L. 
C. B. Molion, and M. N. G. Ribeiro, 1991: Post-deforestation Amazonian climate: Anglo-Brazilian research to improve prediction. J. Hydrol., 129, 71-085.

Sun, Z., and L. Rikus, 1999: Improved application of exponential sum fitting transmissions to inhomogeneous atmosphere. J. Geophys. Res., 104D, 6291-6303.

Tiedtke, M., 1989: A comprehensive mass flux scheme for cumulus parameterization in large-scale models. Mon. Wea. Rev., 117, 1779-1800.

Wang, B., and LinHo, 2002: Rainy season of the Asian-Pacific summer monsoon. J. Climate, 15, 386-398.

—, R. Wu, and X. Fu, 2000: Pacific-East Asia teleconnection: How does ENSO affect East Asian climate? J. Climate, 13, 15171536 .

Wang, Y., 1999: A triply nested movable mesh tropical cyclone model with explicit cloud microphysics-TCM3. BMRC Research Rep. 74, 81 pp. [Available from Bureau of Meteorology Research Centre, Melbourne, Australia, VIC 3001.]
_ 2001: An explicit simulation of tropical cyclones with a triply nested movable mesh primitive equation model-TCM3. Part I: Model description and control experiment. Mon. Wea. Rev., 129, $1370-1394$.

_ 2002 : An explicit simulation of tropical cyclones with a triply nested movable mesh primitive equation model-TCM3. Part II: Model refinements and sensitivity to cloud microphysics parameterization. Mon. Wea. Rev., 130, 3022-3036.

-, O. L. Sen, and B. Wang, 2003: A highly resolved regional climate model (IPRC-RegCM) and its simulation of the 1998 severe precipitation event over China. Part I: Model description and verification of simulation. J. Climate, 16, 1721-1738.

$\mathrm{Xu}$, K.-M., and D. A. Randall, 1996: A semiempirical cloudiness parameterization for use in climate models. J. Atmos. Sci., 53, 3084-3102.

Xue, Y., 1996: The impact of desertification in the Mongolian and the inner Mongolian grassland on the regional climate. J. Climate, 9, 2173-2189. 